\title{
Development and Evaluation of the Online Addiction Medicine Certificate: Free Novel Program in a Canadian Setting
}

Lauren Renee Gorfinkel ${ }^{1,2}$, BSc (Hons); Amanda Giesler ${ }^{2}$, MPH; Huiru Dong ${ }^{2,3}$, MSc; Evan Wood ${ }^{2,4}$, MD, PhD; Nadia Fairbairn ${ }^{2,4}$, MD; Jan Klimas ${ }^{2,4,5}$, MSc, PhD

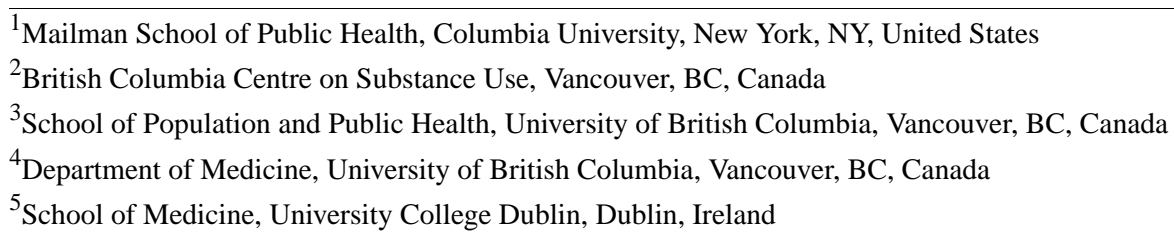

Corresponding Author:

Jan Klimas, MSc, PhD

British Columbia Centre on Substance Use

400-1045 Howe St

Vancouver, BC, V6Z 2A9

Canada

Phone: 1 (778) 9457616

Email: jan.klimas@bccsu.ubc.ca

\section{Abstract}

Background: Despite the enormous burden of disease attributable to drug and alcohol addiction, there remain major challenges in implementing evidence-based addiction care and treatment modalities. This is partly because of a persistent lack of accessible, specialized training in addiction medicine. In response, a new online certificate in addiction medicine has been established in Vancouver, Canada, free of charge to participants globally.

Objective: The objective of this study was to evaluate and examine changes in knowledge acquisition among health care professionals before and after the completion of an online certificate in addiction medicine.

Methods: Learners enrolled in a 17-module certificate program and completed pre- and postknowledge tests using online multiple-choice questionnaires. Knowledge acquisition was then evaluated using a repeated measures $t$ test of mean test scores before and after the online course. Following the certificate completion, a subset of learners completed the online course evaluation form.

Results: Of the total 6985 participants who registered for the online course between May 15, 2017 and February 22, 2018,3466 (49.62\%) completed the online pretest questionnaire. A total of 1010 participants completed the full course, achieving the required $70 \%$ scores. TThe participants self-reported working in a broad range of health-related fields, including nursing ( $\mathrm{n}=371)$, medicine $(n=92)$, counseling or social work $(n=69)$, community health $(n=44)$, and pharmacy $(n=34)$. The median graduation year was $2010(n=363$, interquartile range 2002-2015). Knowledge of the addiction medicine increased significantly postcertificate (mean difference $28.21 ; 95 \%$ CI 27.32 to $29.10 ; P<.001)$. Physicians scored significantly higher on the pretest than any other health discipline, whereas the greatest improvement in scores was seen in the counseling professions and community outreach.

Conclusions: This free, online, open-access certificate in addiction medicine appeared to improve knowledge of learners from a variety of disciplines and backgrounds. Scaling up low threshold learning opportunities may further advance addiction medicine training, thereby helping to narrow the evidence-to-practice gap.

(JMIR Med Educ 2019;5(1):e12474) doi: 10.2196/12474

\section{KEYWORDS}

medical education; substance-related disorders; education, distance 


\section{Introduction}

\section{Background}

Approximately 29 million people are affected by substance use disorders (SUDs) annually [1], with an estimated 21 billion dollars of associated productivity losses in the United States alone [2]. In recent years, a sharp rise in opioid-related deaths has led to numerous public health emergency declarations, and the number of alcohol use disorders is increasing globally [3-5]. Still, uptake of evidence-based SUD treatment is low and people with SUDs often receive inadequate care [6]. This is despite recent progress in addiction science, which has highlighted the important role of skilled health care providers and the efficacy of established psychosocial and pharmacological therapies in improving treatment outcomes [1,6-8]. Moreover, most health care providers frequently report feeling unprepared to effectively identify and treat SUDs, and the stigma toward persons with SUDs persists among the health professions [9-11].

To address these gaps in practice, health professionals need better education and training in addiction medicine. However, such specialized training programs can be inaccessible because of limited space, inability to compensate participants for their time, and the location of training (often big, urban centers) [12-15]. In addition, many of these programs accept only a particular subset of health care professionals-for instance, only physicians or social workers-and have limited resources for expansion. At the same time, effectively training a variety of health care providers in evidence-based treatment of SUDs is critical for providing quality care, as well as curbing the current opioid epidemic. One solution to overcome these challenges is the expansion of online training programs, which can reach a large number of participants, train professionals from a wide range of health disciplines, be delivered at a relatively low cost, and can be accessed from a wide variety of settings [16,17]. Although the literature suggests that online continuing professional development courses in health care can be equally effective as traditional classroom-based courses [17-19], this has not been demonstrated for addiction medicine.

\section{Objectives}

We sought to evaluate changes in knowledge acquisition before and after the completion of a new, comprehensive, and accredited online certificate in addiction medicine, accessible and free of charge to learners worldwide.

\section{Methods}

\section{Course Description}

The Addiction Care and Treatment Online Certificate is a free course and certificate program open for anyone wishing to improve their knowledge of substance use, although it is targeted at health professionals. The course involves 17 modules related to the identification, management, and treatment of SUDs. Textbox 1 lists the course learning objectives and topics covered. Each module is comprised a 20- to 75-min video lecture (including a slideshow with spoken voice-over) by an expert in the relevant topic. Each module (with the exception of modules 1 and 17) is then followed by a brief multiple-choice test of the module material. All multiple-choice questions are in single best answer format with 4 answer options. Those looking to obtain a formal certificate and Continuing Medical Education certificate must complete all the modules, achieving a minimum passing score of $70 \%$ on all postmodule tests. Overall, the online course takes approximately 16 hours to complete; however, it is self-paced, so learners can complete each module in their own time. Modules do not have to be completed in chronological order, allowing learners to select the topics that most interest or benefit them. Once learners complete the course, they must pass through an online evaluation form (with one mandatory question on potential bias in course content) to receive a digital certificate.

Before release, this course was accredited via review and approval by the University of British Columbia Division of Continuing Professional Development. This required a formal committee with representation of the target audience, a high degree of evidence, and no industry bias or involvement. The course also met the certification criteria of the College of Family Physicians of Canada, as well as Maintenance of Certification Program of The Royal College of Physicians and Surgeons of Canada.

\section{Course Development and Background}

On the basis of the informal and formal consultations with a range of stakeholders by the course's planning committee, it was clear that there was a general lack of awareness of the range of evidence-based treatments for SUDs. Specifically, there was an unmet need for specific education and training for health care professionals on SUDs that was accessible and provided at no cost. In response to this need, the British Columbia Centre on Substance Use (BCCSU) developed this structured course in partnership with content experts throughout British Columbia. This included physicians in the areas of psychiatry, public health, internal medicine, and family medicine. Although the target audience of the program is primarily prescribers, modules were created to be accessible to all allied health disciplines, including nurses, social workers, psychologists, and were also accessible for a general audience.

The course design utilizes a case-based learning structure, with theoretical and academic context nested in the introductions to the module. The topics, content, and speakers were selected through recommendations and advice from the planning committee. Each module is taught by a faculty member who has extensive experience with the particular topic and would be considered an expert in the province. Physician members of the planning committee were instrumental in ensuring that all materials were evidence-based and relevant to physicians practicing in the primary care environments. Before beginning their presentations, the course's lead author (EW) and the planning committee required faculty members to submit detailed module outlines. These were thoroughly reviewed, and feedback was returned to presenters for incorporation into their lecture and presentation slides. The finalized presentations were then reviewed to ensure validity and objectivity of content. The lectures were recorded between August 2015 to May 2016. The course was hosted on the host center's website using a WordPress content management system. 
Textbox 1. Learning objectives and topics covered in The Addiction Care and Treatment Online Certificate.

Learning objectives

1. Incorporating screening diagnosis and brief intervention and referral to treatment for substance use disorders in clinical practice.

2. Selecting the appropriate pharmacological and psychosocial treatment interventions based on the best evidence, as well as individual patient needs, circumstances, and preferences.

3. Providing safe and effective treatment to patients and their families throughout the induction, maintenance, and/or discontinuation process across the continuum of care for substance use disorders.

4. Setting treatment goal monitoring and evaluating progress and providing patient-centered support across the continuum of care for substance use disorders.

5. Appreciating the complexity of substance use disorders, diversity of care, and providing informed referrals to evidence-based support services.

6. Promoting recovery, safety, wellness, and harm reduction to improve patient care and support for those with substance use disorders.

7. Implementing strategies for safer prescribing practices for medications with abuse/diversion potent (ie, opioids for analgesia, benzodiazepines, etc).

Topics or modules (time in module)

1. Introduction to addiction medicine $(20 \mathrm{~min})$

2. Screening, diagnosis, and brief intervention for substance use disorders (45 $\mathrm{min}$ )

3. Opioid use disorder (50 min)

4. Tobacco use disorder (45 min)

5. Alcohol use disorder (35 $\mathrm{min})$

6. Withdrawal syndromes (60 min)

7. Stimulant use disorder $(20 \mathrm{~min})$

8. Polysubstance use (65 min)

9. Comorbid mental illness and substance use disorders (35 min)

10. Pain and substance use disorders (65 $\mathrm{min})$

11. Common medical complications (45 min)

12. Safe prescribing $(75 \mathrm{~min})$

13. Overdose prevention and harm reduction (45 min)

14. Psychosocial interventions (50 min)

15. Addiction in the workplace $(75 \mathrm{~min})$

16. Recovery oriented systems of care (30 min)

17. Cases consolidating knowledge ( $35 \mathrm{~min}$ )

The course leads and advisory committee guide the ongoing, year-round recruitment activities. Participant recruitment strategies include disseminating advertisements through electronic mailing lists, posters, brochures, descriptions and links on the bccsu.ca website, lay media advertisements, conference participation, newsletters, social media, and word of mouth. In addition, the course was promoted through in-person seminars focused on substance use across Canada.

\section{Procedures}

To take the online course, participants first had to register using the online registration form. Here, learners were given space to fill in their full name and email address and were asked to select their home province from a drop-down menu (all Canadian provinces and Other were listed). Providing province information became mandatory after the first month of the course. In the registration form, learners were also asked to select their professional discipline from a given list. Following registration, learners completed a multiple-choice knowledge test (the pretest) to evaluate baseline knowledge of course content. In addition, following each module, learners completed multiple-choice knowledge tests (the posttests) to evaluate the understanding of the material just taught.

As 2 of the modules (1 and 17, the introduction and conclusion) lacked posttests, to pass the online course, learners had to complete a total of 15 posttests. When all posttests were completed with a minimum $70 \%$ score, learners were then given the option to complete an online evaluation form, gauging their satisfaction with the program and the applicability of course material to their clinical practice. The evaluation form also asked for further demographic information, such as professional discipline, the year that learners completed their professional degrees, and the health care settings in which they provide services. 
Textbox 2. Sample question and format.

Question: Evidence-based first-line anticraving and relapse prevention therapies for the treatment of alcohol use disorder include: (1) Naltrexone 50 mg once daily; (2) Acamprosate 666 mg once daily; (3) Gabapentin 300 mg once daily; (4) Celexa 40 mg once daily.

Correct answer: 1

Explanation: Naltrexone is typically provided $50 \mathrm{mg}$ once daily and has a number needed to treat to prevent a return to any drinking of 20 . Acamprosate has a number needed to treat to prevent a return to any drinking of 12 and is an alternative first-line agent, but it is dosed $666 \mathrm{mg} 3$ times per day rather than once daily. Though less studied, Gabapentin appears to be an effective anticraving agent but the optimal studied dose was $600 \mathrm{mg} 3$ times per day. Celexa is not a pharmacotherapy for alcohol use disorder.

Citations:

1. Jonas DE et al. Pharmacotherapy for adults with alcohol use disorders in outpatient settings: a systematic review and meta-analysis. JAMA. 2014 May 14;311(18):1889-900.

2. Mason BJ et al. Gabapentin treatment for alcohol dependence: a randomized clinical trial. JAMA Intern Med. 2014 Jan;174(1):70-7.

\section{Survey Development}

Questions on pre- and posttests were collaboratively developed by the course's lead author (EW) and the lecturers. Questions were updated by the course coordinator (AG), BCCSU staff, and experienced clinicians in addiction medicine. All pre- and posttests used a multiple-choice format and were designed to measure changes in learners' knowledge of addiction medicine and SUDs. The pretest contains 30 knowledge questions of material from all course modules. Each posttest contains 3 to 10 multiple-choice questions, covering only material from the relevant module. Textbox 2 represents the question format adhered to in this course. Although all pretest questions were asked postcourse, it was impossible for these questions to be matched item-to-item with the pretest results, because of the online platform setup. Although a minimum score of $70 \%$ was required to pass each posttest, there was no such requirement for the 30-item pretest. Learners can also attempt posttests multiple times, resulting in the number of learners passing each module being unequal to the number of all recorded attempts at each posttest. As a result of learner feedback, some posttest questions were altered over the course of the study period. For example, changes were made to the phrasing of questions in the module Alcohol Use Disorder.

This study was approved by the Research Ethics Board at Providence Health Care Research Institute, University of British Columbia. All participants were informed of the study purpose, as well as the voluntary and anonymous nature of participation before signing the informed electronic consent.

\section{Data Analysis}

Data from the course registration and pre- and posttests were linked using participants' full names and email addresses. Using registration data, participants were divided into 7 broad health-related fields: (1) medicine, (2) nursing, (3) pharmacy, (4) counseling/social work, (5) community outreach/support work, (6) residents/students, and (7) other.

We measured the effectiveness of the course using (1) completion rate (percentage of participants who attempted all 15 posttests out of the total number of participants registered), (2) success rate (percentage of participants who successfully passed all 15 posttests out of the total number of participants who attempted all 15 posttests), (3) commitment rate (percentage of participants who passed all 15 posttests out of the total number of participants who attempted at least one posttest), and (4) mean difference between the assessments at the start (pretest) and at the end (posttests) of the online course. The pretest score was used as a proxy for precourse knowledge and the mean of all posttest scores was used as an indicator of the overall postcourse knowledge. A repeated measures design with $t$ tests of mean scores on pre- and posttests therefore evaluated positive knowledge acquisition in participants who completed all 15 posttests. Scores on all tests were measured in percentage terms. When a participant attempted a posttest more than once, the mean score from all attempts by that participant was taken (not only those which surpassed 70\%), so as to keep one posttest value per participant and module.

We also examined differences in test scores between participants in different health-related fields (eg, nursing, pharmacy). Health professionals with significantly greater pretest scores were taken to have greater baseline knowledge than other health professionals taking the course. In addition, health professionals with a significantly greater difference in scores were taken to have had greater knowledge benefits than other health professionals taking the course. Linear regression and paired $t$ tests were used to test statistical significance of these differences with SAS 9.4 (SAS Institute). All $P$ values were 2 -sided.

\section{Results}

\section{Registration and Participant Characteristics}

Between May 15, 2017 and February 22, 2018, a total of 6985 persons registered for the course. During this period, there was a steady linear increase in the total number of course registrations, with a particularly sharp rise in the number of nurses (Figure 1). Of those who registered, 3466 completed the pretest and attempted at least one module's posttest. A total of 1010 then attempted every posttest at least once, all of whom achieved the minimum passing score of $70 \%$ on one attempt of each test. Therefore, the course had a completion rate of $14.45 \%$, a success rate of $100 \%$, and a commitment rate of $29.14 \%$. 
Figure 1. Total number of registrations in the online addiction medicine certificate from May 2017 to February 2018, stratified by professional discipline (N=6985). Jan: January; Feb: February; Jun: June; Jul: July; Aug: August; Sep: September; Oct: October; Nov: November; Dec: December.

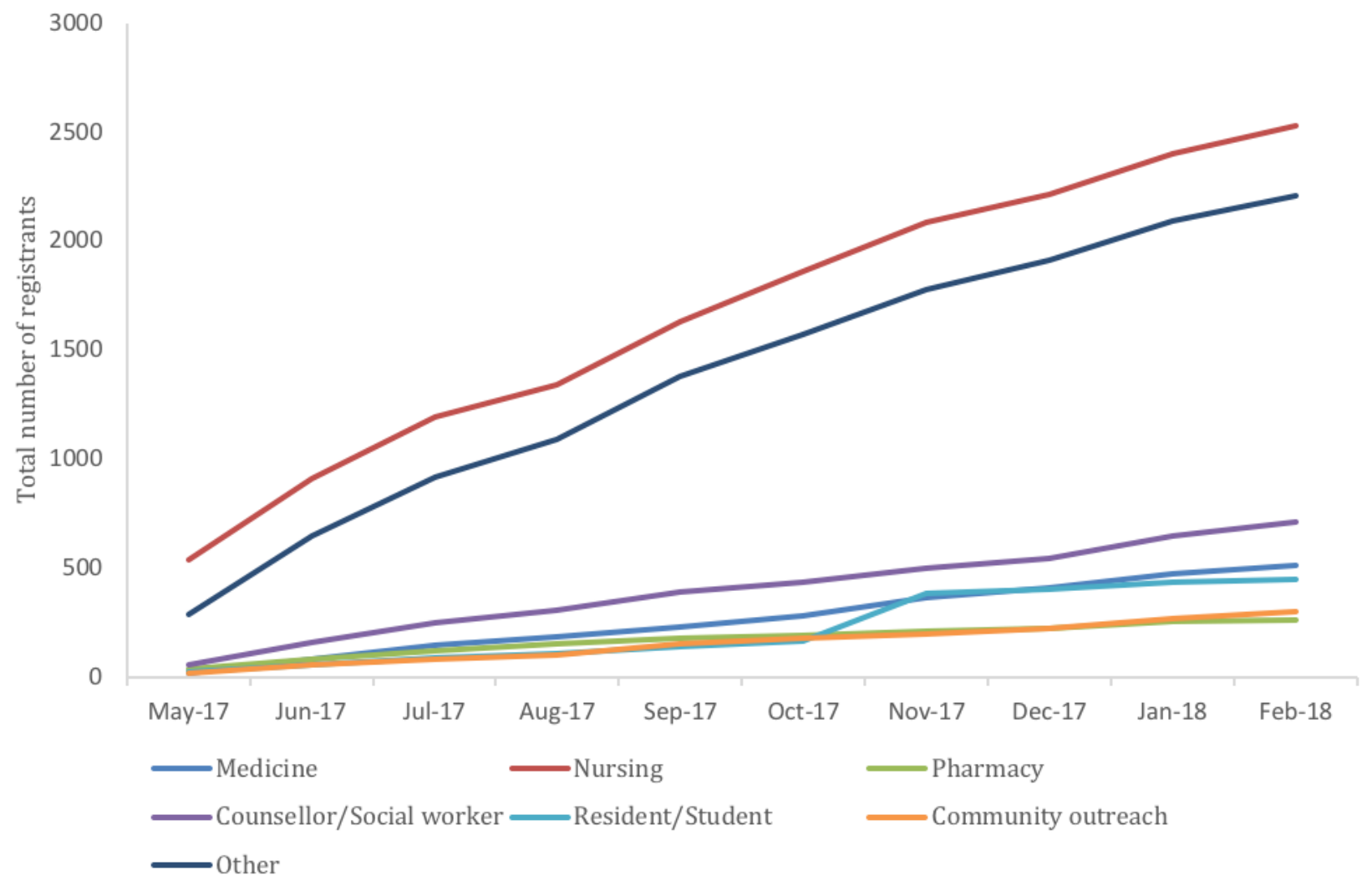

Among the 1010 course completers, participants self-reported working in a broad range of health-related fields, mostly nursing $(371 / 1010,36.73 \%)$ and medicine $(92 / 1010,9.11 \%$; Table 1$)$. There was an overall difference in the province of origin between those who did and did not complete the course $(P=.013)$, with a higher proportion of Ontarians and Prairie residents among completers versus noncompleters (Table 1).

\section{Knowledge of Addiction Medicine}

Attempting (regardless of pass/fail status) all 15 modules with posttests was a study inclusion criterion. However, as all learners who attempted every module also passed the course, a total of 1010 attempters were included in the analyses.

Postcertificate, the knowledge of addiction medicine increased significantly (mean difference 28.2; 95\% CI 27.3 to 29.1; $P<.001$; Table 2). Physicians scored between 6.9 and 10.6 percentage points higher on the pretest than other health disciplines. The greatest improvement in scores was seen in the counseling and community outreach professions (Table 3). 
Table 1. Sociodemographic characteristics of the sample, with $P$ values, stratified by certificate completion status.

\begin{tabular}{|c|c|c|c|c|}
\hline \multirow[t]{2}{*}{ Characteristic } & \multirow[t]{2}{*}{ Total $(\mathrm{N}=3466), \mathrm{n}(\%)$} & \multicolumn{2}{|c|}{ Completion status, $\mathrm{n}(\%)$} & \multirow[t]{2}{*}{$P$ value } \\
\hline & & $\begin{array}{l}\text { Completers } \\
(\mathrm{n}=1010)\end{array}$ & $\begin{array}{l}\text { Ongoing learners }{ }^{\mathrm{a}} \\
(\mathrm{n}=2456)\end{array}$ & \\
\hline Province & & & & .013 \\
\hline British Columbia & $1371(39.56)$ & $362(35.84)$ & $1009(41.08)$ & \\
\hline Prairie provinces $(\mathrm{SK}, \mathrm{MB}, \mathrm{AB})^{\mathrm{b}}$ & $716(20.66)$ & $237(23.47)$ & $479(19.50)$ & \\
\hline Ontario & $237(6.84)$ & $71(7.03)$ & $166(6.76)$ & \\
\hline Quebec/Atlantic regions $(\mathrm{NB}, \mathrm{NL}, \mathrm{NS}, \mathrm{PEI})^{\mathrm{c}}$ & $101(2.91)$ & $24(2.38)$ & $77(3.14)$ & \\
\hline Missing/other ${ }^{\mathrm{d}}$ & $1041(30.03)$ & $316(31.29)$ & $725(29.52)$ & \\
\hline Self-identified discipline & & & & $<.001$ \\
\hline Medicine & $274(7.91)$ & $92(9.11)$ & $182(7.41)$ & \\
\hline Nursing & $1265(36.50)$ & $371(36.73)$ & $894(36.40)$ & \\
\hline Counseling or social work & $346(9.98)$ & $69(6.83)$ & $277(11.28)$ & \\
\hline Pharmacy & $124(3.58)$ & $34(3.37)$ & $90(3.66)$ & \\
\hline Student or resident & $239(6.90)$ & $61(6.04)$ & $178(7.25)$ & \\
\hline Community outreach & $167(4.82)$ & $44(4.36)$ & $123(5.01)$ & \\
\hline Other & $1051(30.32)$ & $339(33.56)$ & $712(28.99)$ & \\
\hline Practice setting $^{e}(n=475)$ & & & & $-^{\mathrm{f}}$ \\
\hline Community-based organization & - & $99(17.3)$ & - & \\
\hline Physician office-based practice & - & $64(11.2)$ & - & \\
\hline Private drug treatment clinic & - & $18(3.1)$ & - & \\
\hline Provincial health authority & - & $152(26.6)$ & - & \\
\hline Community health center & - & $101(17.7)$ & - & \\
\hline Other ${ }^{\mathrm{g}}$ & - & $138(24.1)$ & - & \\
\hline
\end{tabular}

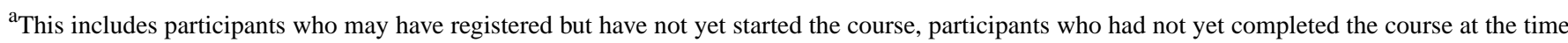
of data collection, and participants who completed the course but did not pass.

${ }^{\mathrm{b}} \mathrm{SK}$ : Saskatchewan; MB: Manitoba; AB: Alberta.

${ }^{\mathrm{c}}$ NB: New Brunswick; NL: Newfoundland; NS: Nova Scotia; PEI: Prince Edward Island.

${ }^{\mathrm{d}}$ This includes participants from international settings, as well as those with missing location data.

${ }^{\mathrm{e}}$ Only participants who passed the course filled in this information in the satisfaction form; totals do not add up to 475 as participants could select more than one service setting.

${ }^{\mathrm{f}}$ Not applicable.

${ }^{\mathrm{g}}$ Other settings included hospitals, mental health facilities, pharmacies, group homes, and more. 
Table 2. Knowledge in addiction medicine among learners completing the free online certificate $(n=1010)$.

\begin{tabular}{|c|c|}
\hline Module & Statistics \\
\hline Pretest total, mean percentage score (SD) & $52.6(14.5)$ \\
\hline \multicolumn{2}{|l|}{ Posttest scores per module, mean percentage score (SD) } \\
\hline Screening, diagnosis, and brief interventions & $84.9(14.3)$ \\
\hline Opioid use disorder & $78.1(21.7)$ \\
\hline Tobacco use disorder & $88.3(15.4)$ \\
\hline Alcohol use disorder & $75.1(23.2)$ \\
\hline Withdrawal syndromes & $79.6(21.9)$ \\
\hline Stimulant use disorder & $76.5(19.1)$ \\
\hline Polysubstance use & $75.1(26.5)$ \\
\hline Comorbid mental illness and substance use disorder & $77.1(24.8)$ \\
\hline Pain and substance use disorders & $77.8(22.6)$ \\
\hline Common medical complications & $78.1(21.9)$ \\
\hline Safe prescribing & $74.1(24.3)$ \\
\hline Overdose prevention and harm reduction & $83.5(22.0)$ \\
\hline Psychosocial interventions & $81.9(18.0)$ \\
\hline Addiction in the workplace & $85.5(17.5)$ \\
\hline Recovery-oriented systems of care & $81.4(18.0)$ \\
\hline Posttest total, mean percentage score (SD) & $80.8(8.7)$ \\
\hline Mean difference between total pre- and posttest scores (95\% CI) & $28.2^{\mathrm{a}}(27.3-29.1)$ \\
\hline
\end{tabular}

${ }^{\mathrm{a}} P<.001$.

Table 3. Pairwise comparisons between medicine and other disciplines on pretest scores and change in score from pre- to posttest ( $\mathrm{n}=1010)$.

\begin{tabular}{lll}
\hline Discipline & Pretest scores, mean difference $(95 \% \text { CI })^{\mathrm{a}}$ & $\begin{array}{l}\text { Change in pre- and posttest scores, } \\
\text { mean difference }(95 \% \mathrm{CI})^{\mathrm{a}}\end{array}$ \\
\hline Medicine & Reference group & $\begin{array}{l}\text { Reference group } \\
\text { Nursing }\end{array}$ \\
Pharmacy & $-8.4^{\mathrm{b}}(-14.1$ to -2.8$)$ & $5.0(-0.7$ to 5.8$)$ \\
Resident/student & $-8.2^{\mathrm{c}}(-12.8$ to -3.6$)$ & $3.3(-1.4$ to 7.9$)$ \\
Counseling/social work & $-7.9^{\mathrm{b}}(-11.1$ to -4.6$)$ & $5.6)$ \\
Community outreach/support worker & $-9.9^{\mathrm{b}}(-14.3$ to -5.4$)$ & $7.9^{\mathrm{e}}(2.7$ to 10.0$)$ \\
Other & $-10.6^{\mathrm{b}}(-15.8$ to -5.5$)$ & $2.3(-1.0$ to 5.6$)$ \\
\hline
\end{tabular}

\footnotetext{
${ }^{a}$ Negative mean difference signifies a score/change in scores lower than that of the reference group. Positive mean difference signifies a score/change in scores higher than that of the reference group.

${ }^{\mathrm{b}} P<.001$.

${ }^{\mathrm{c}} P=.003$.

${ }^{\mathrm{d}} P=.015$.

${ }^{\mathrm{e}} P=.003$.

A subset of 475 participants $(47.0 \%)$ completed the course satisfaction form. The most commonly reported service settings were provincial health authorities, community health centers, and community-based organizations (Figure 1). The median graduation year was $2010 \quad(n=363$, interquartile range

course evaluation either agreed or strongly agreed that the course successfully met their learning needs. In addition, the majority of the participants rated the course's relevance to their practice $(83 \%)$ and incorporation of evidence-based research (93\%) as above average or excellent (Table 4).
} 2002-2015). Most (89\%) of the participants who completed the 
Table 4. Participant responses to select evaluation criteria for the Addiction Care and Treatment Online Certificate.

\begin{tabular}{|c|c|c|c|c|c|c|}
\hline \multirow[t]{2}{*}{ Statement } & \multicolumn{6}{|l|}{ Rating (\%) } \\
\hline & $\begin{array}{l}\text { Strongly disagree / } \\
\text { Poor }\end{array}$ & $\begin{array}{l}\text { Disagree / Below } \\
\text { average }\end{array}$ & Neutral / Average & $\begin{array}{l}\text { Agree / Above } \\
\text { average }\end{array}$ & $\begin{array}{l}\text { Strongly agree / } \\
\text { Excellent }\end{array}$ & Not applicable \\
\hline $\begin{array}{l}\text { This course was effective in meet- } \\
\text { ing my learning needs }\end{array}$ & 2.5 & 1.7 & 5.3 & 33.3 & 54.5 & 2.7 \\
\hline Relevance to my practice & 0.2 & 1.9 & 12.6 & 38.9 & 43.3 & 3 \\
\hline $\begin{array}{l}\text { Incorporation of evidence-based } \\
\text { research }\end{array}$ & 0.2 & 0.2 & 4.8 & 33.2 & 57.9 & 3.6 \\
\hline
\end{tabular}

\section{Discussion}

\section{Principal Findings}

We sought to evaluate the changes in knowledge acquisition before and after completion of a comprehensive online certificate in addiction medicine. Following the course, the knowledge of addiction medicine increased significantly, with a completion rate of $14.5 \%$ (percentage of participants who attempted all 15 posttests out of the total number of participants registered), success rate of $100 \%$ (percentage of participants who successfully passed all 15 posttests out of the total number of participants who attempted all 15 postests), and commitment rate of $29.1 \%$ (percentage of participants who passed all 15 posttests out of the total number of participants who attempted at least one posttest). Physicians scored significantly higher on the pretest than any other health discipline, whereas the greatest improvement in scores was seen in the counseling professions and community outreach. A majority of participants reported that the course was effective in meeting their learning needs, was relevant to their practice, and well-incorporated evidence-based research.

This course is a novel online training program in addiction medicine-a field in urgent need of expanded educational opportunities for health care providers $[9,10,20]$. As of February 2018, the course had nearly 7000 registrants, confirming the strength of low threshold, online models for facilitating rapid scale-up of evidence-informed training in addiction medicine, and a high demand [21-23]. This demand was particularly notable among nurses who composed the largest proportion of health providers in our sample and saw the sharpest increase in registrations. As reported in previous papers [24], the completion rates of open online courses are often lower than those of traditional in-person training, and this may be more a product of participants' individual preferences or needs, rather than the course material or structure. As such, the observed completion rate of this course is in line with previous studies of open online courses, which report completion rates from $0.9 \%$ to $36.1 \%$ (median 6.5\%) [24,25]. It is also important to note that the online certificate in addiction medicine was intentionally structured for participants to select the modules most relevant to them.

Similar to previous studies of online courses on SUDs, we found a significant increase in knowledge of addiction medicine postcertificate $[22,23,26,27]$. In addition, this study highlighted which health professions may derive the most benefit from such a course. Aligned with prior literature, which has shown that education in SUD care is often lacking in social work and counseling curricula $[22,28]$, participants in counseling/social work and community outreach demonstrated the greatest improvement in scores. For example, in one study of university-level counseling and social work programs, it was found that just $69 \%$ of masters-level counseling programs, $3 \%$ of bachelors-level social work programs, and $2 \%$ of masters-level social work programs required a course in SUD care [29]. Still, the online format can present unique barriers-including time- and schedule-constraints - as noted by previous studies of online training in SUDs [30].

\section{Limitations}

Several limitations may reduce the generalizability of our findings. First, because of the inconsistencies in the data, for some participants, it was impossible to link their course registration data and test scores. Second, the large number of participants from western Canada may have introduced bias into the results, as health care professionals' knowledge and training in addiction medicine may vary by setting. Promoting the course to a more international audience could improve training and highlight the needs of health care professionals in a wider range of contexts. Third, the self-selection of registrants for the course may mean that the study participants were more likely to have a higher level of interest or experience in addiction medicine-it is likely that practitioners who seek specialized training are more prone to positive attitudes toward, and learning experiences with people who have SUDs [31]. Fourth, as participants were able to attempt each postmodule test as many times as they liked, and a minimum score of $70 \%$ was required to pass each test, our overall posttest value may have been positively skewed. This limitation was carefully considered before analyses, balancing perspectives that a participant's final passing attempt at each posttest (1) represented new retained knowledge and (2) was the product of selecting the correct answer by chance. Therefore, we averaged the scores from all attempts by a single participant at each posttest. This mean score was then used to calculate a total group mean score for the course. Finally, we did not capture a corresponding change in provider behavior following the course. Future research examining the impact of this course in addiction care settings would be valuable.

\section{Conclusions}

In this study, over 6000 participants began and over 1000 participants completed online training in addiction medicine. Overall, our analyses suggest that the course can feasibly increase knowledge in addiction medicine to a wide range of health care providers. Scaling up low threshold learning 
opportunities may further advance addiction medicine training, thereby helping to narrow the evidence-to-practice gap.

\section{Acknowledgments}

The authors would like to thank Leslie Lappalainen, Christy Sutherland, Milan Khara, Paul Sobey, Mark McLean, Thomas Kerr, Venu Karapeddy, Nick Mathews, Launette Rieb, Seonaid Nolan, Rashmi Chadha, Jane Buxton, Annabel Mead, Paul Farnan, and Marshall Smith for their authorship of course content. For their contributions on the planning and delivery of the course, the authors would also like to thank Elaine Fernandes, Mike T O’Shaughnessy, Cheyenne Johnson, Emily Wagner, Nirupa Goel, Fernando Prado, and Keith Ahamad. This study was supported by the United States National Institutes of Health (R25DA037756). Funding for the creation of the online course was supplied by the Government of British Columbia, Ministry of Health. This research was undertaken, in part, thanks to funding from the Canada Research Chairs program through a Tier 1 Canada Research Chair in Inner City Medicine that supports EW. A European Commission grant (701698) supports JK. A grant from the Michael Smith Foundation for Health Research supports NF.

\section{Conflicts of Interest}

None declared.

\section{References}

1. United Nations Office on Drugs and Crime. 2016. World Drug Report 2016 URL: https://www.unodc.org/doc/wdr2016/ WORLD DRUG REPORT 2016 web.pdf [accessed 2019-05-14] [WebCite Cache ID 78MPilpIh]

2. Florence CL, Zhou C, Luo F, Xu L. The economic burden of prescription opioid overdose, abuse, and dependence in the United States, 2013. Med Care 2016 Dec;54(10):901-906 [FREE Full text] [doi: 10.1097/MLR.0000000000000625] [Medline: 27623005]

3. World Health Organization. 2014. The global status report on alcohol health 2014 URL: https://www.who.int/sorry/ [accessed 2019-05-14] [WebCite Cache ID 78MPoUBgA]

4. The Lancet. The opioid crisis in the USA: a public health emergency. The Lancet 2017 Nov;390(10107):2016. [doi: 10.1016/S0140-6736(17)32808-8]

5. British Columbia Centre for Disease Control (BCCDC). 2017 Sep. Public health emergency in BC URL: http://www. bccdc.ca/about/news-stories/stories/public-health-emergency-in-bc [accessed 2019-05-14] [WebCite Cache ID 78MYDHt41]

6. Centre on Addiction. 2012 Jun. Closing the gap between science and practice URL: https://www.centeronaddiction.org/ sites/default/files/Addiction-medicine-closing-the-gap-between-science-and-practice_1.pdf [accessed 2019-05-14] [WebCite Cache ID 78MQ1wyfG]

7. van Boekel LC, Brouwers EP, van Weeghel J, Garretsen HF. Healthcare professionals' regard towards working with patients with substance use disorders: comparison of primary care, general psychiatry and specialist addiction services. Drug Alcohol Depend 2014 Jan 01;134:92-98. [doi: 10.1016/j.drugalcdep.2013.09.012] [Medline: 24099970]

8. O'Connor PG, Sokol RJ, D'Onofrio G. Addiction medicine: the birth of a new discipline. JAMA Intern Med 2014 Nov;174(11):1717-1718. [doi: 10.1001/jamainternmed.2014.4211] [Medline: 25201642]

9. Herbeck DM, Hser YI, Teruya C. Empirically supported substance abuse treatment approaches: a survey of treatment providers' perspectives and practices. Addict Behav 2008 May;33(5):699-712 [FREE Full text] [doi: 10.1016/j.addbeh.2007.12.003] [Medline: 18207334]

10. Ayu AP, Schellekens AF, Iskandar S, Pinxten L, De Jong CA. Effectiveness and organization of addiction medicine training across the globe. Eur Addict Res 2015;21(5):223-239 [FREE Full text] [doi: 10.1159/000381671] [Medline: 25966903]

11. Wakeman SE, Pham-Kanter G, Donelan K. Attitudes, practices, and preparedness to care for patients with substance use disorder: results from a survey of general internists. Subst Abus 2016;37(4):635-641. [doi: 10.1080/08897077.2016.1187240] [Medline: 27164025]

12. Ayu AP, Schellekens AF, Iskandar S, Pinxten L, de Jong CA. The Development of a National Training Program on Addiction Medicine in Indonesia. In: Textbook of Addiction Treatment: International Perspectives. Milano: Springer; 2015.

13. Klimas J, Ahamad K, Fairgrieve C, McLean M, Mead A, Nolan S, et al. Impact of a brief addiction medicine training experience on knowledge self-assessment among medical learners. Subst Abus 2017;38(2):141-144 [FREE Full text] [doi: 10.1080/08897077.2017.1296055] [Medline: 28394732]

14. Tong S, Sabo R, Aycock R, Prasad R, Etz R, Kuzel A, et al. Assessment of addiction medicine training in family medicine residency programs: a CERA study. Fam Med 2017 Jul;49(7):537-543 [FREE Full text] [Medline: 28724151]

15. Voon P, Johnson C, Small W, Wood E, Klimas J. Nursing fellowship in addiction medicine: a novel program in a Canadian setting. J Addict Nurs 2017;28(3):148-149. [doi: 10.1097/JAN.0000000000000179] [Medline: 28863057]

16. Selby P, Goncharenko K, Barker M, Fahim M, Timothy V, Dragonetti R, et al. Review and evaluation of online tobacco dependence treatment training programs for health care practitioners. J Med Internet Res 2015 Apr 17;17(4):e97 [FREE Full text] [doi: 10.2196/jmir.3284] [Medline: 25887187] 
17. Liyanagunawardena TR, Williams A. Massive open online courses on health and medicine: review. J Med Internet Res 2014 Aug 14;16(8):e191 [FREE Full text] [doi: 10.2196/jmir.3439] [Medline: 25123952]

18. Cook DA, Levinson AJ, Garside S, Dupras DM, Erwin PJ, Montori VM. Internet-based learning in the health professions: a meta-analysis. J Am Med Assoc 2008 Sep 10;300(10):1181-1196. [doi: 10.1001/jama.300.10.1181] [Medline: 18780847]

19. Lam-Antoniades M, Ratnapalan S, Tait G. Electronic continuing education in the health professions: an update on evidence from RCTs. J Contin Educ Health Prof 2009;29(1):44-51. [doi: 10.1002/chp.20005] [Medline: 19288566]

20. Klimas J. Training in addiction medicine should be standardised and scaled up. Br Med J 2015 Jul 28;351:h4027 [FREE Full text] [doi: 10.1136/bmj.h4027] [Medline: 26220548]

21. Covell NH, Covell PJ, Smith MF, Merrens MR, Essock SM. Distance training and implementation supports to scale up integrated treatment for people with co-occurring mental health and substance use disorders. J Dual Diagn 2011;7(3):162-172. [doi: 10.1080/15504263.2011.593157]

22. Larson M, Amodeo M, Storti SA, Steketee G, Blitzman G, Smith L. A novel CBT web course for the substance abuse workforce: community counselors' perceptions. Subst Abus 2009;30(1):26-39 [FREE Full text] [doi: 10.1080/08897070802611741] [Medline: 19197779]

23. Weingardt K, Cucciare MA, Bellotti C, Lai WP. A randomized trial comparing two models of web-based training in cognitive-behavioral therapy for substance abuse counselors. J Subst Abuse Treat 2009 Oct;37(3):219-227 [FREE Full text] [doi: 10.1016/j.jsat.2009.01.002] [Medline: 19339136]

24. Onah DF, Sinclair J, Boyatt R. Dropout rates of massive open online courses. 2014 Presented at: The 6th International Conference on Education and New Learning Technologies; July 2014; Barcelona, Spain p. 5825-5834.

25. Jordan K. Initial trends in enrolment and completion of massive open online courses. IRRODL 2014;15(1). [doi: 10.19173/irrodl.v15i1.1651]

26. Matejkowski J, Dugosh KL, Clements NT, Festinger DS. Pilot testing of an online training for criminal justice professionals on medication-assisted treatment. J Addict Offender 2015;36(1):13-27. [doi: 10.1002/j.2161-1874.2015.00032.x]

27. Sholomskas DE, Carroll KM. One small step for manuals: computer-assisted training in twelve-step facilitation. J Stud Alcohol 2006 Nov;67(6):939-945 [FREE Full text] [Medline: 17061013]

28. Bartholomew NG, Joe GW, Rowan-Szal GA, Simpson DD. Counselor assessments of training and adoption barriers. J Subst Abuse Treat 2007 Sep;33(2):193-199 [FREE Full text] [doi: 10.1016/j.jsat.2007.01.005] [Medline: 17434707]

29. Russett JL, Williams A. An exploration of substance abuse course offerings for students in counseling and social work programs. Subst Abus 2015;36(1):51-58. [doi: 10.1080/08897077.2014.933153] [Medline: 25010520]

30. Curran G, Woo SM, Hepner KA, Lai WP, Kramer TL, Drummond KL, et al. Training substance use disorder counselors in cognitive behavioral therapy for depression: development and initial exploration of an online training program. J Subst Abuse Treat 2015 Nov;58:33-42. [doi: 10.1016/j.jsat.2015.05.008] [Medline: 26219680]

31. Strang J, Hunt C, Gerada C, Marsden J. What difference does training make? A randomized trial with waiting-list control of general practitioners seeking advanced training in drug misuse. Addiction 2007 Oct;102(10):1637-1647. [doi: 10.1111/j.1360-0443.2007.01929.x] [Medline: 17662105 ]

\section{Abbreviations \\ BCCSU: British Columbia Centre on Substance Use \\ SUD: substance use disorder}

Edited by G Eysenbach; submitted 10.10.18; peer-reviewed by G Bury, M Dahl, J Wilkinson; comments to author 27.02.19; revised
version received 19.04.19; accepted 21.04.19; published 24.05.19
Please cite as:
Gorfinkel LR, Giesler A, Dong H, Wood E, Fairbairn N, Klimas J
Development and Evaluation of the Online Addiction Medicine Certificate: Free Novel Program in a Canadian Setting
JMIR Med Educ 2019;5(1):e12474
URL: $\underline{\text { http://mededu.jmir.org/2019/1/e12474/ }}$
doi: $\underline{10.2196 / 12474}$
PMID: $\underline{31127722}$

CLauren Renee Gorfinkel, Amanda Giesler, Huiru Dong, Evan Wood, Nadia Fairbairn, Jan Klimas. Originally published in JMIR Medical Education (http://mededu.jmir.org), 24.05.2019. This is an open-access article distributed under the terms of the Creative Commons Attribution License (https://creativecommons.org/licenses/by/4.0/), which permits unrestricted use, distribution, and reproduction in any medium, provided the original work, first published in JMIR Medical Education, is properly cited. The 
complete bibliographic information, a link to the original publication on http://mededu.jmir.org/, as well as this copyright and license information must be included. 